\title{
Mesangioproliferative glomerulonephritis with extracapillary crescents - unexpected fatal complication in a 17-year-old patient with implanted left ventricular assist device
}

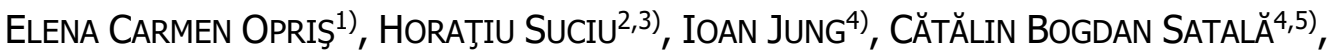

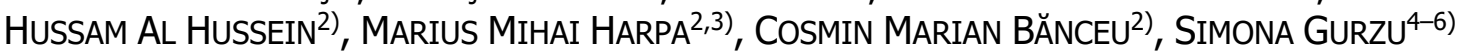 \\ 1) Master Student, Department of Adult and Children Cardiovascular Recovery, Emergency Institute for Cardiovascular \\ Diseases and Transplantation, Târgu Mureş, Romania \\ 2) Department of Adult and Children Cardiac Surgery, Emergency Institute for Cardiovascular Diseases and Transplantation, \\ Târgu Mureş, Romania \\ 3) Department of Surgery, George Emil Palade University of Medicine, Pharmacy, Sciences and Technology of Târgu Mureş, \\ Romania \\ 4) Department of Pathology, George Emil Palade University of Medicine, Pharmacy, Science and Technology of Târgu Mureş, \\ Romania \\ 5) Department of Pathology, Emergency County Hospital, Târgu Mureş, Romania \\ 6) Laboratory of Microscopy, Center for Advanced Medical and Pharmaceutical Research, George Emil Palade University \\ of Medicine, Pharmacy, Science and Technology of Târgu Mureş, Romania
}

\begin{abstract}
The continuous flow left ventricular assist device (cf-LVAD) is the life-saving solution for patients with end-stage global heart failure. We present the case of a young patient with biventricular dilated cardiomyopathy, who had a cf-LVAD implantation and died as result of progressive renal failure. In the first year after implantation, he suffered repeated strokes and episodes of pneumonia with Klebsiella pneumoniae and Escherichia coli. The patient had hypertension, which was kept under control with angiotensin-converting enzyme (ACE) inhibitors and beta-blockers. After multiple bleeding episodes, the patient died at 21 months after the LVAD implant. At autopsy, parenchymatous brain hemorrhage was found to be associated with pulmonary hemorrhages. The unexpected features related to mesangioproliferative and extracapillary glomerulonephritis, with focal glomerulosclerosis. The proliferated parietal cells of Bowman's capsule proved to express cluster of differentiation 44 (CD44), whereas remnant podocytes and mesangial cells showed Wilms tumor 1 (WT1) positivity. Since CD44 might be involved in fibrogenesis, but ACE inhibitors can exert a protective role against glomerular deterioration, we performed a synthesis of literature data which enabled us to propose a hypothesis with a potential clinical impact. We conclude that, in patients with LVAD implants, high blood pressure and high serum level of angiotensin II, the association between ACE inhibitors and anti-CD44 agents might exert glomerular protection and increase the survival time. Experimental studies are necessary to support our hypothesis and to explain the mechanism of possible glomerulopathy installed after LVAD implant.
\end{abstract}

Keywords: glomerulonephritis, CD44, WT1, left ventricular assist device, cardiomyopathy, glomerulopathy.

\section{口 Introduction}

In young males, dilated cardiomyopathy is one of the common causes of global heart failure [1-3]. In the general population, it was reported a prevalence of 1:2500 cases and an incidence of 1:18 000 cases per year [1]. Without transplantation, cardiogenic shock occurs in half of the patients $[2,3]$.

Given the low availability of heart transplantation, a good option for these patients is implantation of a left ventricular assist device (LVAD), which is commonly known as the "artificial heart" [3, 4]. The LVAD is a mechanical continuous flow pump (cf-LVAD) that can replace the pump function of the left ventricle (LV). It can improve systemic perfusion, with further remission of heart failure phenomena [4]. The number of implanted cases is increasing, but the complications that often occur are difficult to treat and are sometimes fatal. It has been shown that in LVAD-implanted patients, the survival rate is $81 \%$ in the first year after implant, $70 \%$ after two years,
$60 \%$ after three years, and only $48 \%$ after four years $[4,5]$.

The high incidence of LVAD-related complications is poorly understood. Such complications are registered in $60 \%$ of patients in the first six months, and up to $80 \%$ of patients in the first two years $[4,5]$. For this reason, a non-transplanted patient has a high risk of death after a mean period of 20 months after LVAD implantation. The mechanism of progressive deterioration is still not completely known.

\section{Aim}

In this paper, we present a representative case of a young patient who died 21 months after implantation of a cf-LVAD, for dilated cardiomyopathy. The clinical history and histopathological autopsy findings are presented in detail, along with a review of the literature in the field of LVAD-induced glomerular lesions. Based on histological and immunohistochemical (IHC) features, a hypothesis of the mechanism of LVAD-related glomerulopathy, with potential clinical impact, is also presented.

This is an open-access article distributed under the terms of a Creative Commons Attribution-NonCommercial-ShareAlike 4.0 International Public License, which permits unrestricted use, adaptation, distribution and reproduction in any medium, non-commercially, provided the new creations are licensed under identical terms as the original work and the original work is properly cited. 


\section{ㅁ Case presentation}

Signed informed consent of the legal tutors was obtained for accessing medical data and publication of the scientific details.

\section{Clinical history}

Four years before the admission described in this paper, a 13-year-old male patient, known to have idiopathic biventricular dilated cardiomyopathy, was registered in our Emergency Institute for Cardiovascular Diseases and Transplantation. He was included on the waiting list for heart transplantation. After two years, his condition worsened and presented the clinical picture of cardiogenic shock. At that time, he was urgently hospitalized, intubated and ventilated, with extracorporeal membrane oxygenation (ECMO) back-up. As the creatinine level was slightly elevated, he also needed renal support. A cf-LVAD was implanted at another clinic.

In the early postoperative phase, the pump's power consumption increased. This was an indicator of possible pump thrombosis. Unfractionated heparin and systemic thrombolysis with tissue plasminogen activator (tPA) was carried out. As the pump function did not improve, it was replaced with another pump six days after LVAD implantation. After another two weeks, a transient stroke and mild pancreatitis were diagnosed, without significant complications. In the early and late postoperative days, several bleeding episodes occurred, one with cardiac tamponade, which required reintervention.

During hospitalization, the patient presented with a fever $\left(38^{\circ} \mathrm{C}\right)$ and elevated serum levels of C-reactive protein $(\mathrm{CRP}>200 \mathrm{mg} / \mathrm{dL}$; normal range $<5 \mathrm{mg} / \mathrm{dL})$. As a sputum culture was positive for Klebsiella pneumoniae and coliform bacilli, Meropenem and Vancomycin were administrated with good results.

After obtaining normal LVAD function, progressively increasing systemic blood pressure required the longterm administration of Enalapril $20 \mathrm{mg}$ bis in die (BID twice a day) and Bisoprolol $5 \mathrm{mg}$ quaque die (QD - once a day). As renal function improved after the LVAD implant, there was no need for diuretics at discharge.

No other significant or uncontrolled events occurred in the first year. At 12 months after the LVAD implant, the patient suffered two episodes of brain hemorrhage, for which he was hospitalized and operated on twice in the Clinic of Neurosurgery, without sequelae. In the following six months, he had another three small hemorrhagic strokes causing hemianopsia, without motor deficit. He also showed repeated episodes of kidney decompensation, with serum creatinine levels up to $2.7 \mathrm{mg} \%$ (normal ranges $0.6-1.2 \mathrm{mg} \%$ ). This was kept under control with diuretics.

The patient neglected to have properly monitored coagulation parameters in the ambulatory and did not regularly control the blood pressure values.

\section{Present admission}

\section{Clinical findings}

At 18 months after LVAD implant, the 17-year-old normosthenic male was hospitalized with the suspicion of acute appendicitis. We noted altered general status, intense abdominal pain, headache, dyspnea, and fatigue after limited physical effort. On admission, the patient was conscious, partially cooperative and without fever. Cardio-respiratory function was checked: pump sound was detected with cardiac auscultation, there was no palpable peripheral pulse, mild peripheral edema, no pulmonary crackles. The medium systolic blood pressure was $100 \mathrm{mmHg}$. On palpation of the abdomen, there was no muscular defense, but the liver was enlarged.

The patient was undergoing therapy with antihypertensive medication, which included an angiotensinconverting enzyme (ACE) inhibitor (Enalapril $20 \mathrm{mg}$ BID) and alpha-beta blocker (Carvedilol $12.5 \mathrm{mg}$ BID). Longterm treatment with an antiaggregant (Aspirin $100 \mathrm{mg}$ QD), an anticoagulant [Acenocoumarol QD for international normalized ratio (INR) 2-3], a diuretic (Furosemide $40 \mathrm{mg}$ QD) and a proton pump inhibitor (Omeprazole $20 \mathrm{mg}$ BID), was also declared.

\section{Laboratory examinations}

On admission, the hematological and serum biochemical analyses showed a compensated renal function (creatinine $-1.13 \mathrm{mg} / \mathrm{dL}$, creatinine clearance $-98 \mathrm{~mL} / \mathrm{min}$, urea $36.8 \mathrm{mg} \%)$, with mild elevated uric acid $(9.81 \mathrm{mg} \%$, with normal ranges of 3.5-7.2 $\mathrm{mg} / \mathrm{dL}$ ). Liver enzymes were within normal ranges, with serum glutamic-oxaloacetic transaminase (GOT) of $9 \mathrm{IU} / \mathrm{L}$ (normal ranges 5-34 IU/L) and glutamate-pyruvate transaminase (GPT) of $6 \mathrm{IU} / \mathrm{L}$ (normal value $<55 \mathrm{IU} / \mathrm{L}$ ), same as the value of total bilirubin $(0.47 \mathrm{mg} / \mathrm{dL})$.

A slightly high level of serum procalcitonin $(1 \mathrm{ng} / \mathrm{mL}$, with normal range $<0.5 \mathrm{ng} / \mathrm{mL}$ ), and a normal value of lactate dehydrogenase (LDH), respectively $110 \mathrm{mg} / \mathrm{dL}$, were also reported. An acute infection was dismissed by normal serum level of CRP $(5 \mathrm{mg} / \mathrm{dL})$ and total leukocytes, which were $6000 / \mu \mathrm{L}$ (normal values 3600-10 000/ $\mu \mathrm{L}$ ) [6].

Coagulation parameters showed a poorly controlled risk of hemorrhage, with an INR value of 5.4, under anticoagulant treatment (reference for INR: 2-3). This was associated with normal platelets $(275000 / \mu \mathrm{L}$; normal range $150000-450000 / \mu \mathrm{L})$ and low hemoglobin values $(8.6 \mathrm{~g} / \mathrm{dL}$; normal ranges $11-17 \mathrm{~g} / \mathrm{dL}$ ).

During hospitalization, the laboratory examinations indicated the progressive development of multiple organ failure syndrome (MOFS). Two weeks after admission, renal failure was proved by the following parameters: high creatinine $(9.02 \mathrm{mg} \%)$; low creatinine clearance (10 mL/min; normal reference ranges $107-139 \mathrm{~mL} / \mathrm{min})$; uremia (235 mg\%); hypoproteinemia (plasma proteins: $5 \mathrm{~g} / \mathrm{dL}$; normal values $6.4-8.3 \mathrm{~g} / \mathrm{dL}$ ); low plasma albumin $(2.2 \mathrm{~g} / \mathrm{dL}$; normal values $3.5-5.2 \mathrm{~g} / \mathrm{dL})$; high uric acid (17.66 mg\%). Liver enzymes were kept within normal ranges (GOT - $23 \mathrm{IU} / \mathrm{L}, \mathrm{GPT}-17 \mathrm{IU} / \mathrm{L})$, with progressively increasing total bilirubin $(2.02 \mathrm{mg} / \mathrm{dL})$ and LDH $(222 \mathrm{mg} / \mathrm{dL})$ and normal values of leukocytes $(9120 / \mu \mathrm{L})$. Hemoglobin decreased to $6.8 \mathrm{~g} / \mathrm{L}$.

The urine test detected hematuria, proteinuria and leukocyturia, without detection of nitrites, bilirubin, or urobilinogen and without modification of the urine density (1.025; normal values 1.005-1.030).

\section{Imagistic investigations}

On admission, chest $\mathrm{X}$-rays showed no modifications of the lungs, a dilated heart and the LVAD in the apex of the LV. An electrocardiogram revealed left fascicular hemiblock and right bundle branch block, with a heart 
rate of 80 beats/min (bpm). The echocardiography showed dilatation of all ventricular and atrial cavities, with decreased ejection fraction (EF) of the LV at 10\% (normal value $>60 \%$ ). Moderate hypokinetic right ventricle, mitral and tricuspid regurgitation was diagnosed, with properly working inflow cannula at the apex of the LV.

Abdominal ultrasound examination detected hepatosplenomegaly and enlarged kidneys, with increased echogenicity of the renal cortex. A pseudo-nodular lesion was described at the lower splenic pole, without enlargement of the appendix. In the first days, the computed tomography (CT) examination of the cranial cavity did not show acute parenchymatous lesions but confirmed the patient's history of repeated strokes. Through the $38 / 33 \mathrm{~mm}$ (centrocentral/latero-lateral) right parietal craniotomy orifice, minimal extracranial herniation of the brain tissue was obvious. Hypodense lesion located at the level of the left lentiform nucleus and at the body of the left caudate nucleus, was suggestive of a healed ischemic stroke, with associated porencephalia (Figure 1, A-C).
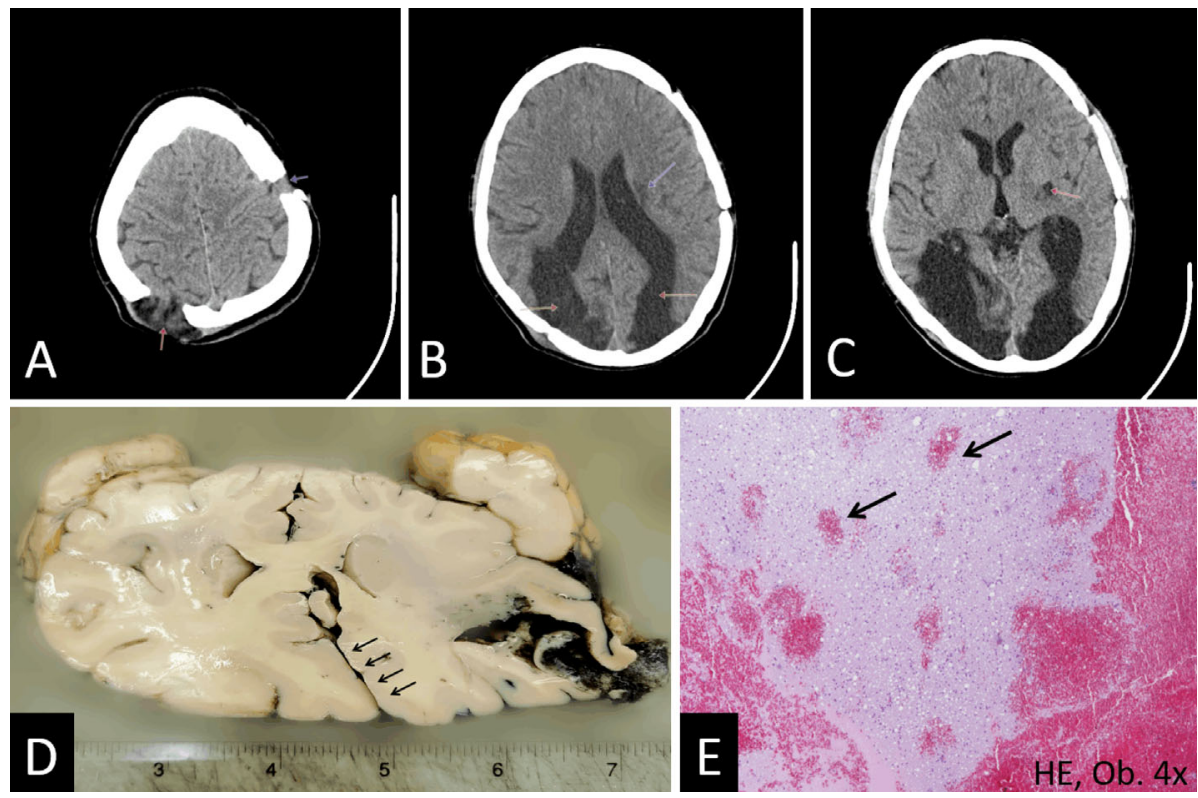

Figure 1 - Brain lesions in a patient with LVAD: (A) At CT scan examination, on the trephination orifices, minimum extracranial hernias can be observed at the level of right craniectomy (red arrow) and of the drill hole (blue arrow); (B) Porencephalic cavities show communications with the lateral ventricles (red arrows) and reactive gliomatosis in the body of the caudate nucleus (blue arrow); (C) The mass effect upon ventricles and reactive gliomatosis (red arrows); (D) At autopsy, the right cerebral hemisphere parenchymatous hematoma proved to exert mass effect, pushing the median line towards the opposite site (arrows); (E) Parenchymatous hemorrhage is associated with multiple diapedesis hemorrhage (arrows). CT: Computed tomography; LVAD: Left ventricular assist device.

During the three months of hospitalization, CT scans performed during the seizures revealed new hemorrhagic outbreaks. In the last stages, chest X-ray showed diffuse veiling of both lung areas, which were treated as a bronchopneumonia.

\section{Diagnosis, therapy, and evolution}

Based on clinical and paraclinical examinations, the case was interpreted on admission as decompensated right heart failure with poor control of anticoagulation parameters in a patient with an LVAD implant.

To prevent stroke and pump thrombosis in patients with LVAD implants, the systolic blood pressure should be maintained at a mean value of $70-80 \mathrm{mmHg}$ [7-9]. To achieve this, it was necessary to add the calcium blocker Amlodipine (10 mg QD) to the ACE inhibitor and alpha-beta blocker. The INR values were controlled with anticoagulants. Persistent headache with episodes of seizures and increased intracranial pressure were treated with osmotic diuretics (Mannitol) and neuroprotectors.

Although an initial improvement was obtained, it was followed by the gradual deterioration of the general condition of the patient, with increased intensity of the headache. Hepato-renal failure occurred at two weeks after admission, followed by episodes of hemoptysis and worsening of peripheral edema. Blood pressure progressively collapsed, with gradual reduction of diuresis, up to $500 \mathrm{~mL} /$ day, and positive inotropic treatment with Dobutamine was needed.

The LVAD controller indicated low flow alarms. The repeated echocardiography revealed significant dilatation of the ventricular and atrial cavities, with worsening of the right heart failure. Antibiotics, hepatoprotectives, gastroprotectives and analgesics, at progressively increasing doses, completed diuretic treatment on continuous infusion.

At the final stage, MOFS occurred. Continuous venovenous hemofiltration $(\mathrm{CVVH})$ was initiated but, after 48 hours, the fatal cerebral hemorrhage was diagnosed. Death occurred three months after the final admission, 21 months after the LVAD implant.

\section{Autopsy findings}

The trephination orifices in the skull, which were performed over six months before the final admission, were identified in the occipital and temporal areas, with mild brain herniation. In the edematous brain parenchyma, reactive gliosis was confirmed under the microscope, as corresponding to these orifices. In the fronto-parietal area, multiple foci of parenchymatous hemorrhages were observed, the largest hematoma being $65 \times 45 \mathrm{~mm}$, which exerted mass effect over the median line. Multiple diapedesis hemorrhages were also seen (Figure 1, D and E). 
Regarding the heart, the LVAD from the apex of the LV did not associate signs of thrombosis or dehiscence. Iatrogenic pericardial adherences were identified. The heart weight was $882 \mathrm{~g}$, with dilatation of the cavities, causing secondary mitral and tricuspid insufficiency. No coronarosclerosis or thrombosis of the coronary arteries was observed. Histological findings consisted of marked fibrosis of the myocardium, along with a focus of septic abscess located at the level of the anterior wall of the LV (Figure 2, A and B).
Examination of the lungs and respiratory tract revealed bilateral dystelectasia, which was clearly visible on the background of a brown parenchyma. Under the microscope, disseminated hemorrhages, with siderophages inside the alveolar spaces, which were colored in blue with Perls Prussian Blue staining, were admixed with neutrophils. Acute respiratory distress syndrome (ARDS) was proved by the presence of focal hyaline membranes upon alveolar septa, as indicators of shock lung (Figure 3, A-F).
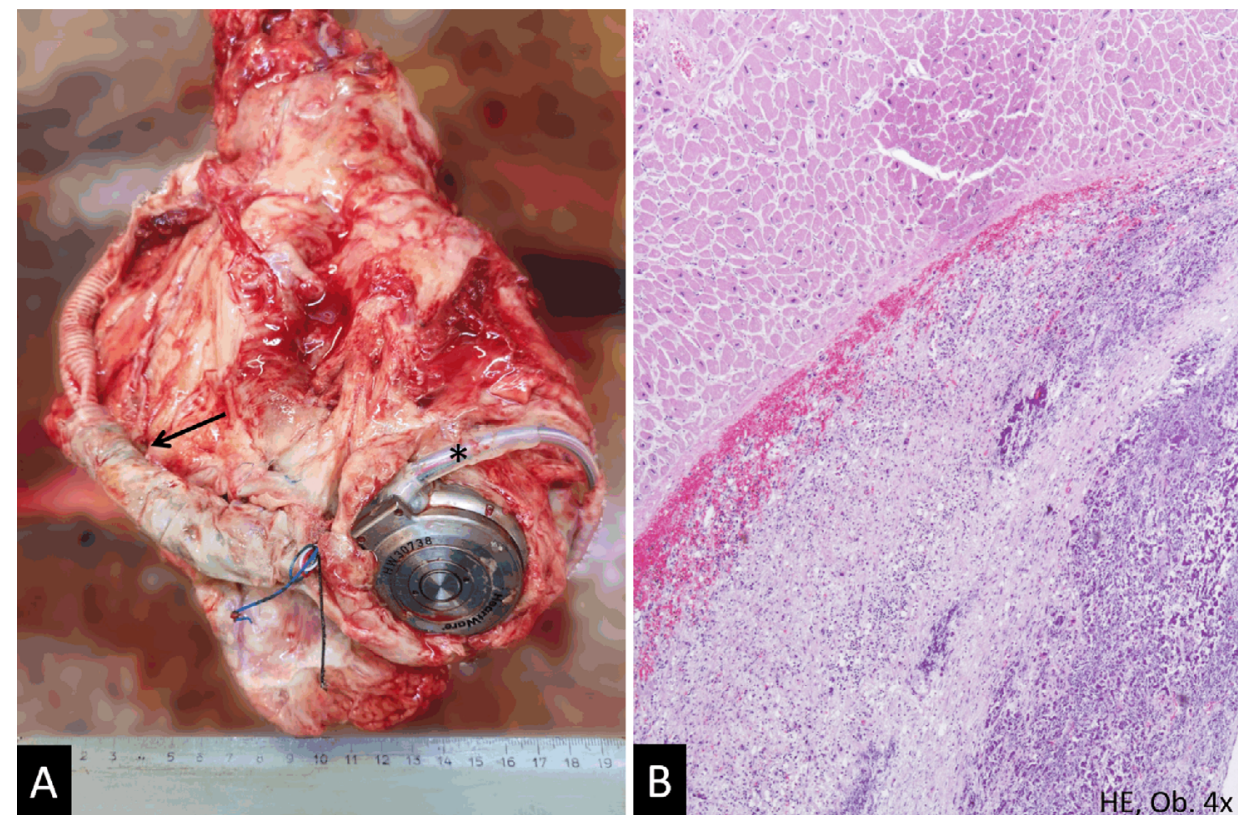

Figure 2 - Heart aspect at autopsy. (A) Macroscopically, no dehiscence or thrombosis of the LVAD are present, but pericardium adherences are observed. LVAD is attached at the level of the apex of the left ventricle. The Dacron tube emerging from the LVAD forms anastomosis with the ascending aorta (arrow), and the electric alimentation cable (*). (B) Histological examination shows a myocardial abscess. LVAD: Left ventricular assist device.
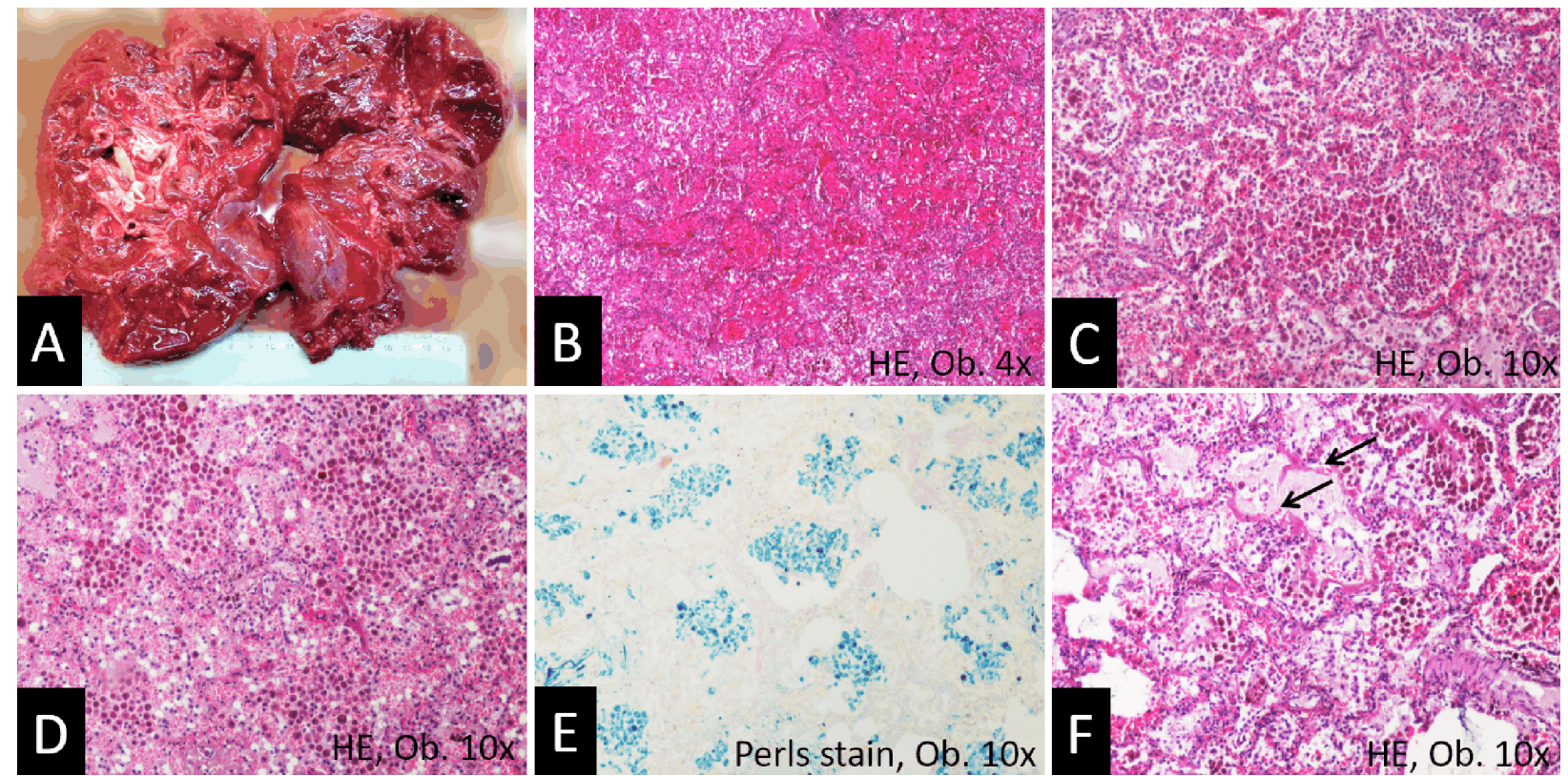

Figure 3 - The aspects of shock lung with severe hemorrhages: (A) Brown hemorrhagic parenchyma, with dystelectasis and high friability; $(B-E)$ Lung hemorrhages, with erythrocytes and siderophages, colored in brown with $H E(C$ and $D)$ and in blue with the specific histochemical staining for iron (E), admixed with neutrophils; $(F)$ Focal hyaline membranes (arrows) indicates an acute respiratory distress syndrome. HE: Hematoxylin-Eosin.

Centrilobular liver necrosis suggested the diagnosis of shock liver. The $380 \mathrm{~g}$ spleen showed, on the cut section, a $40 \times 20 \times 10 \mathrm{~mm}$ triangular, yellowish area, which was confirmed under the microscope as a superinfected splenic infarction.

The enlarged kidneys (left $-380 \mathrm{~g}$; right $-355 \mathrm{~g})$ showed, on cut section, changes compatible with a diagnosis of shock kidney, i.e., medullary hyperemia and a pale, ischemic renal cortex. Microscopic analysis confirmed the diagnosis of shock kidney. Routine Hematoxylin-Eosin (HE) staining also revealed extensive glomerular changes, which consisted of an enlarged mesangial area, with focal 
glomerular sclerosis, highlighted in green with Masson's trichrome staining. Crescentic proliferation of parietal cells
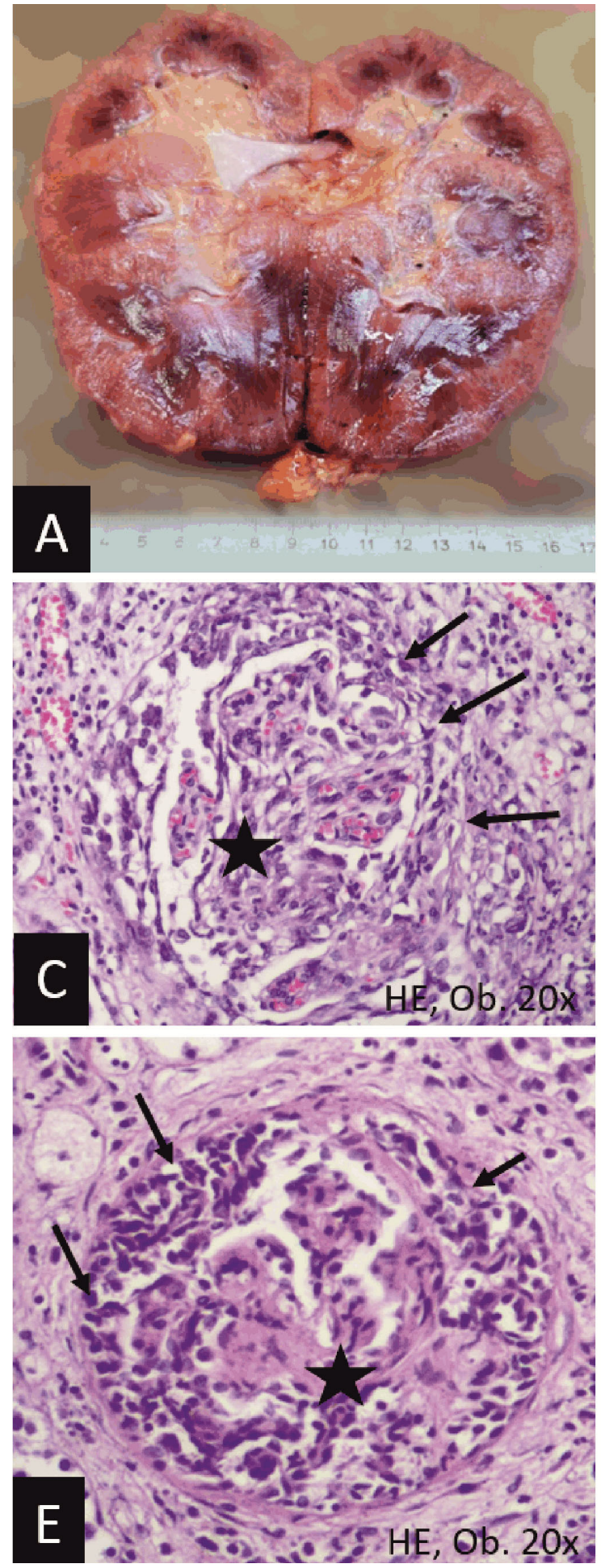

of Bowman's capsule was observed, without neutrophils. Interstitial nephritis was also documented (Figure 4, A-F).
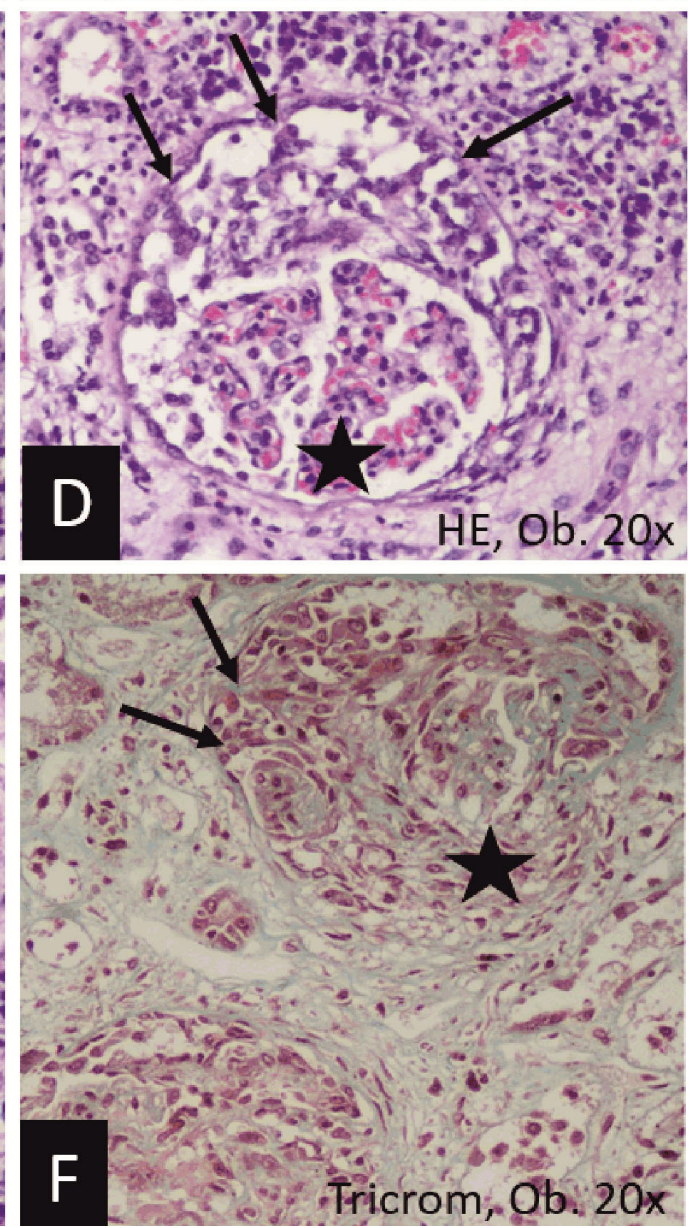

Figure 4 - Gross aspect and microscopically characteristics of mesangioproliferative glomerulonephritis with extracapillary component, at autopsy: (A) Enlarged kidney, with hyperemic medulla, as an indicator of shock kidney; (B) Proliferative glomerulonephritis involves almost all of the glomeruli; (C) Mesangial enlargement (*) is accompanied by crescentic proliferation of parietal cells of Bowman's capsule (arrows); (D) A glomerulus with predominance of extracapillary proliferation (arrows) is accompanied by interstitial nephritis with mononuclear cells; (E and F) Predominance of segmental mesangial glomerulosclerosis (*), which is marked in green with Masson's trichrome staining $(F)$.

In paraffin-embedded kidney parenchyma tissue, IHC stainings were also performed. We used the cell-cell adhesion marker cluster of differentiation (CD) 44 (Dako ${ }^{\circ}$, Denmark, 1:50 dilution, sodium citrate $\mathrm{pH} 6$ retrieval), Wilms' tumor 1 (WT1) protein antibody (Dako ${ }^{\circ}$, Denmark, ready-to-use, high $\mathrm{pH}$ retrieval) and the stem cells-related markers CD133 (Millipore ${ }^{\odot}$, Denmark, 1:50 dilution, high $\mathrm{pH}$ retrieval) and octamer-binding transcription factor-3/4 $\left(\right.$ Oct-3/4) $\left(\right.$ Leica $^{\mathcal{O}}, \mathrm{UK}, 1: 50$ dilution, high $\mathrm{pH}$ retrieval). In the affected glomeruli, CD44 proved to mark the 
proliferated parietal cells, while WT1 positivity was clearly (Figure 5, A-D). No positivity for CD133 or Oct-3/4 was seen in the remnant podocytes and the mesangial cells highlighted.

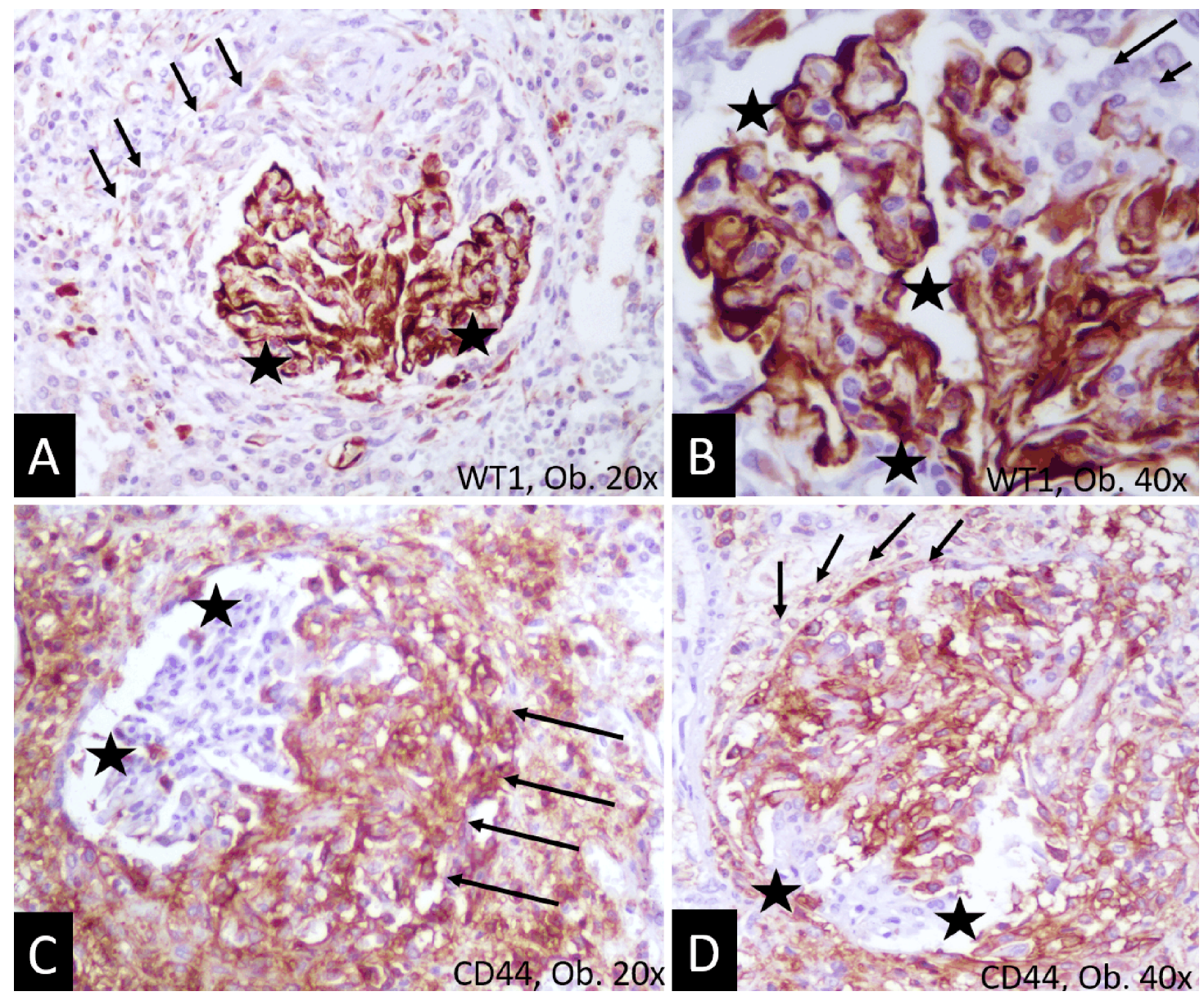

Figure 5 - Immunohistochemical profile of glomeruli components, in mesangioproliferative glomerulonephritis, with extracapillary crescents: (A and B) The WT1 expression is seen in remnant podocytes and mesangial cells (*) but is not expressed by proliferated parietal cells of Bowman's capsule (arrows); (C and D) The CD44 positivity, contrasting to WT1, is absent in capillary component (*) but marks the extracapillary crescents (arrows). CD44: Cluster of differentiation 44; WT1: Wilms tumor 1.

Based on the above-mentioned autopsy findings, renal failure was explained by a mesangioproliferative glomerulonephritis with extracapillary crescents and segmental glomerulosclerosis. Repeated hemorrhagic episodes, associated with terminal hemorrhagic pneumonia, also contributed to progressive degradation of the general status.

\section{Discussions}

One third of patients with cardiac global heart failure also exhibit chronic kidney disease [10-12]. After LVAD implantation, improvement of the renal flow is usually obtained in the early postoperative phase. At the same time, to maintain the life of the of LVAD, it is mandatory to have normal renal function. For every $1 \mathrm{~mL} / \mathrm{min}$ below creatinine clearance of $60 \mathrm{~mL} / \mathrm{min}$, there is a $1 \%$ increase in mortality rate [13]. The incidence of acute kidney failure is $10 \%$ in the first month after implant, $28 \%$ in all LVAD patients and even higher (up to 56\%) in those with pre-existing kidney disease $[14,15]$. The mechanism of renal deterioration after LVAD implant is still unclear.

Experimental studies on animals with normal kidneys prior to LVAD implantation, showed normal renal activity in the first 340 days after implant, with increased plasmatic renin activity [13]. Despite maintaining functionality, the histological changes consisted of arterial wall-smooth muscle cells hyperplasia, periarterial inflammatory cell infiltration and interstitial nephritis, without reported glomerular disorders [13].

Extrapolation of these results to humans is uncertain since the animals had normal ventricular function, unlike the patients requiring LVAD [16]. In our case, mild interstitial nephritis was associated with severe glomerular lesions, which appeared to be the main problem. It was about progressive proliferation of mesangial and parietal cells, with focal glomerulosclerosis.

From a physiopathological perspective, patients with LVAD were found to have gradually decreasing serum levels of atrial natriuretic peptides, aldosterone, renin, and arginine vasopressin $[17,18]$. In patients with LVAD unloading, increased cardiac load leads to diastolic and systolic dysfunction but also increased circulating and myocardial tissue level of angiotensin II, who stimulates fibroblasts [19].

On the other hand, long-term treatment with ACE inhibitors, such as in our case, seems to induce reactivation of ACE activity $[19,20]$. In cardiac insufficiency, the renin-angiotensin-aldosterone system is intensely activated 
and induces vasoconstriction in the efferent arterioles as a renal self-regulation mechanism. However, this mechanism might become exhausted and maladaptation can induce renal deterioration [15, 21]. Maladaptive repair is histologically characterized by interstitial nephritis and accumulation of the extracellular matrix (ECM) [22-24]. Since Kagami et al. (1994) proved that a transforming growth factor-beta (TGF- $\beta$ ) related to proliferation of ECM, followed by glomerulosclerosis [25], we can suppose that, in cases such the one presented in this paper, ACE inhibitors are helpful to maintain normal blood pressure, but after long-term use, they can exert a negative impact upon the renal matrix. TGF- $\beta$ might play a role in remodeling of extracellular collagen matrix and cellular transdifferentiation, which might consist of epithelialmesenchymal or endothelial-mesenchymal transition, with further mesangial matrix enlargement $[19,26]$, such in our case.

In mesangial cells isolated from healthy renal tissues, exogenously added angiotensin II induced sclerotic glomerular changes, which were unrelated to the glomerular pressure. It was proved that the renin-angiotensin system (RAS) stimulates the TGF- $\beta$-induced proliferation of the ECM [25].

WT1 gene proved to play a role in normal functioning of the renal podocytes. In conditionally immortalized human podocyte cell lines from Alb/TGF- $\beta 1$ transgenic mice, reduced expression of WT1 gene was followed by lesion of the podocytes and the appearance of synchronous crescentic glomerulonephritis and mesangial sclerosis. WT1 expression was downregulated by TGF- $\beta 1$ before the onset of glomerulosclerosis [27].

Regarding the CD44, which is a glycoprotein with a role in cell-cell adhesion, it was previously reported that, in renal maladaptive repair, CD44 expression increases in inflammatory kidney disease, being upregulated in crescent glomerulonephritis and injured tubules [28]. CD44 might play a role in the activation of the protein kinase R-like endoplasmic reticulum kinase (pERK) cascade, with further fibrogenesis. Roeder et al. designed an experimental study, inducing focal segmental glomerulosclerosis in CD44 knockout mice and CD44 wildtype mice, and they observed that the migration of parietal cells from Bowman's capsule was present to a lesser extent in the experimental group (CD44 knockout) than in the control group (CD44 wildtype) [29]. This mechanism was also described in diabetic nephropathy and the aged kidney $[29,30]$, but we were not able to find any published paper to demonstrate that this mechanism works in the same way in nephropathy installed after LVAD implantation. In line with the aforementioned experiments, our case showed diffuse positivity for CD44 in the proliferated parietal cells of Bowman's capsule. Further studies are needed to demonstrate whether CD44 positivity might be used as a marker for dismal prognosis in LVADimplanted patients who develop proliferative nephropathy. If this is proved to be the case, blocking of CD44 using monoclonal antibodies, such as Bivatuzumab, usually used in head and neck cancers, may become a therapeutic tool in patients with extracapillary glomerulonephritis [31].

While CD44 has a role in the mechanism of glomerular fibrogenesis through mutual activation with $\mathrm{pERK}$ proteins,
WT1 acts as a transcription factor involved in glomerulosclerosis and is a marker that indicates a podocytopathy. Recent studies have focused on understanding their intricate molecular mechanisms and the way that CD44 and WT1 interact in the process of glomerulosclerosis. The effacement of the podocytes, another crucial event in the pathogenesis of glomerulopathies, is almost invariably present once the process of glomerular fibrosis begins. WT1 proved to be a reliable IHC marker for this event. Recent studies have demonstrated an increasing expression of the parietal cell marker CD44 following WT1-positive podocytes injury $[29,32]$. It was even hypothesized that the CD44positive cells proliferation aims to replace the WT1positive injured podocytes.

Some of the antihypertensive drugs, such as ACE inhibitors, not only appear to exert an anti-apoptotic role and maintain the structure and function of remnant podocytes, but also reduce proliferation of all cell populations within the cellular crescent and reduce glomerulosclerosis severity [33-36]. It is still unknown if administration of these therapeutic agents is able to upregulate WT1 or downregulate CD44 [33-35]. It would be interesting to find out if once WT1 expression is restored, the overexpression of CD44 is diminished.

In the kidney of our patient, which showed an atypical mesangioproliferative and extracapillary form of glomerulosclerosis [37], the proliferated parietal cells expressed CD44, while WT1 positivity was only seen in podocytes and mesangial cells. As renal failure was diagnosed a relatively short time after LVAD implantation, we suppose that a focal proliferative glomerulonephritis was first induced by a systemic infection with Klebsiella pneumoniae and coliform bacilli. At that time, ACE inhibitors probably exerted a glomerular protective role and maintained a relatively good quality of life despite glomerulonephritis. In the last phases, when ACE inhibitors were not enough to maintain normal blood pressure, probably because gradual reactivation of ACE activity occurred [20], the uncontrolled crescentic proliferation of CD44 parietal cells exerted a supplementary compression of glomerular capillary tufts and segmental glomerulosclerosis was expanded. If Kagami's hypothesis is correct, these observations should be accompanied by a parallel decrease in the number of WT1-positive podocytes through immune mechanisms, which might be LVAD-induced. Enddeterioration of the glomeruli function occurred suddenly, with an increase in the creatinine serum level, from 1.13 to $9.2 \mathrm{mg} \%$ in only few days (Figure 6). This representative case confirmed that glomerulonephritis can be silent and can be incidentally diagnosed at autopsy after careful histopathological examination [38].

With a background of renal deterioration, uremia increases the risk of bleeding and can induce brain and lung hemorrhages, such as in our case. In patients with LVAD, a pump-related dysfunction of von Willebrand factor (vWF) can also occur [39], with potential neoangiodysplasia, high vascular fragility, brain microhemorrhages and an increase in peripheral vascular resistance and blood pressure values [9, 40-45]. As bacteremia also increases vascular fragility [42], a mild bacterial infection can be the trigger of MOFS in such patients. 
Infections with

Klebsiella pneumoniae

and Escherichia coli
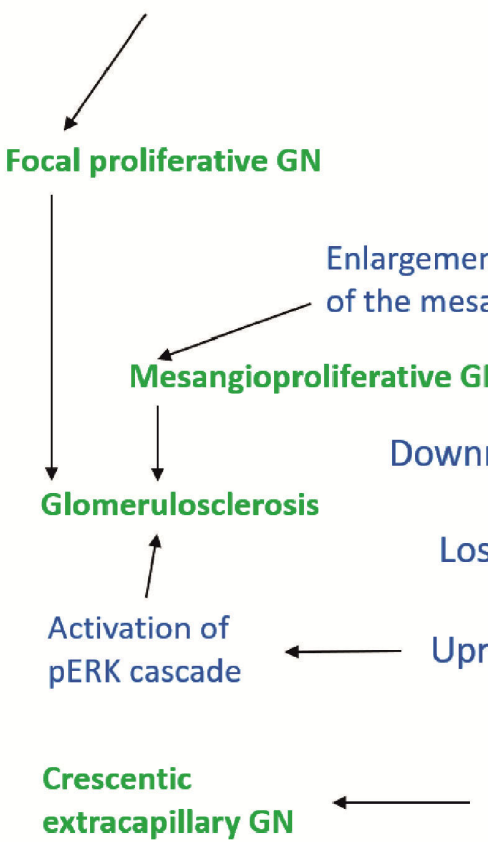

Angiotensinogen

Renin

Angiotensin I

ACE-i
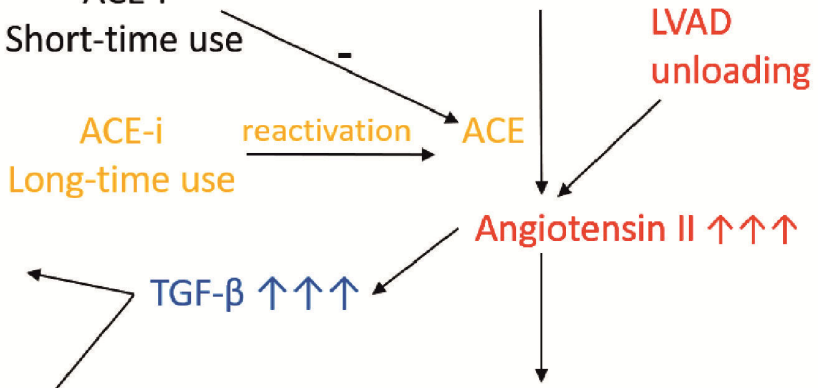

Vasoconstriction

in the afferent arterioles

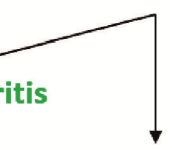

Enlargement of

extracellular matrix

and glomerulosclerosis

Figure 6 - Potential mechanism of progressive glomerulosclerosis in LVAD recipients. The three triggers of GN are infections, LVAD unloading and paradoxical reactivation of ACE, after long-time administration of ACE-i. High serum level of angiotensin II and TGF-ß are the key elements of glomerulosclerosis cascade. ACE: Angiotensin-converting enzyme; ACE-i: ACE inhibitors; CD44: Cluster of differentiation 44; GN: Glomerulonephritis; LVAD: Left ventricular assist device; pERK: Protein kinase R-like endoplasmic reticulum kinase; TGF-ß: Transforming growth factor-beta; WT1: Wilms tumor 1.

\section{Conclusions}

In patients with an LVAD implant, the associated injuries might involve small vessels, predominantly seen in the brain and kidneys. These injuries are not only related to increased fragility, but also to a progressively installed glomerulosclerosis. It seems to occur as result of paradoxically increasing of angiotensin II at both circulating and tissue level, especially in myocardium and glomeruli. To understand the mechanism of multiorgan deterioration which becomes irreversible at about 20 months after LVAD implantation, autopsies are essential. In large cohorts, CD44-related crescentic proliferation of parietal cells with further glomerulosclerosis is necessary to be proved. If they are indeed confirmed, after LVAD implant, the risk of remodeling of extracellular collagen matrix can be decreased through association of CD44targeted molecules and ACE inhibitors. In patients with high serum level of angiotensin II, this association might decrease the risk of glomerulosclerosis and consequently increase the LVAD life.

\section{Conflict of interests}

The authors report no conflict of interests.

\section{Authors' contribution}

Elena Carmen Opriş and Cătălin Bogdan Satală have the same contribution to the paper.

\section{Acknowledgments}

We thanks to all colleagues involved in the management of this difficult case.

The professional team from Academic Proofreading Services Ltd. did the English correction.

\section{References}

[1] Regitz-Zagrosek V, Petrov G, Lehmkuhl E, Smits JM, Babitsch B, Brunhuber C, Jurmann B, Stein J, Schubert C, Merz NB, Lehmkuhl HB, Hetzer R. Heart transplantation in women with dilated cardiomyopathy. Transplantation, 2010, 89(2):236-244. https://doi.org/10.1097/TP.0b013e3181c35255 PMID: 20098289

[2] Jeger RV, Radovanovic D, Hunziker PR, Pfisterer ME, Stauffer JC, Erne P, Urban P; AMIS Plus Registry Investigators. Ten-year trends in the incidence and treatment of cardiogenic shock. Ann Intern Med, 2008, 149(9):618-626. https://10.7326/0003-4819-149-9-200811040-00005 PMID: 18981487

[3] Rose EA, Gelijns AC, Moskowitz AJ, Heitjan DF, Stevenson LW, Dembitsky W, Long JW, Ascheim DD, Tierney AR, Levitan RG, Watson JT, Meier P, Ronan NS, Shapiro PA, Lazar RM, Miller LW, Gupta L, Frazier OH, Desvigne-Nickens P, Oz MC, Poirier VL; Randomized Evaluation of Mechanical Assistance for the Treatment of Congestive Heart Failure (REMATCH) Study Group. Long-term use of a left ventricular assist device for end-stage heart failure. N Engl J Med, 2001, 345(20): 1435-1443. https://doi.org/10.1056/NEJMoa012175 PMID: 11794191

[4] Kirklin JK, Naftel DC, Pagani FD, Kormos RL, Stevenson LW, Blume ED, Myers SL, Miller MA, Baldwin JT, Young JB. 
Seventh INTERMACS Annual Report: 15,000 patients and counting. J Heart Lung Transplant, 2015, 34(12):1495-1504. https://doi.org/10.1016/j.healun.2015.10.003 PMID: 26520247

[5] Wever-Pinzon O, Drakos SG, Kfoury AG, Nativi JN, Gilbert EM, Everitt M, Alharethi R, Brunisholz K, Bader FM, Li DY, Selzman $\mathrm{CH}$, Stehlik J. Morbidity and mortality in heart transplant candidates supported with mechanical circulatory support: is reappraisal of the current United network for organ sharing thoracic organ allocation policy justified? Circulation, 2013, 127(4):452-462. https://doi.org/10.1161/CIRCULATION AHA.112.100123 PMID: 23271796 PMCID: PMC3752367

[6] McKay EJ, Heyes K, Chaggar P, Foden P, Williams S, Bernard J, Yonan N, Venkateswaran R, Shaw SM, Muldoon E. $\mathrm{C}$-reactive protein (CRP) correlates poorly with infection in the post-surgical period following left ventricular assist device (LVAD) implantation. J Heart Lung Transplant, 2017, 36(4 Suppl):S258. https://doi.org/10.1016/j.healun.2017.01.690

[7] Castagna F, Stöhr EJ, Pinsino A, Cockcroft JR, Willey J, Reshad Garan A, Topkara VK, Colombo PC, Yuzefpolskaya M, McDonnell BJ. The unique blood pressures and pulsatility of LVAD patients: current challenges and future opportunities. Curr Hypertens Rep, 2017, 19(10):85. https://doi.org/10.1007/ s11906-017-0782-6 PMID: 29043581 PMCID: PMC5645430

[8] Feldman D, Pamboukian SV, Teuteberg JJ, Birks E, Lietz K, Moore SA, Morgan JA, Arabia F, Bauman ME, Buchholz HW, Deng M, Dickstein ML, El-Banayosy A, Elliot T, Goldstein DJ, Grady KL, Jones K, Hryniewicz K, John R, Kaan A, Kusne S, Loebe M, Massicotte MP, Moazami N, Mohacsi P, Mooney M, Nelson T, Pagani F, Perry W, Potapov EV, Eduardo Rame J, Russell SD, Sorensen EN, Sun B, Strueber M, Mangi AA Petty MG, Rogers J; International Society for Heart and Lung Transplantation. The 2013 International Society for Heart and Lung Transplantation Guidelines for mechanical circulatory support: executive summary. J Heart Lung Transplant, 2013, 32(2):157-187. https://doi.org/10.1016/j.healun.2012.09.013 PMID: 23352391

[9] Willey JZ, Boehme AK, Castagna F, Yuzefpolskaya M, Garan AR, Topkara V, Colombo PC. Hypertension and stroke in patients with left ventricular assist devices (LVADs). Curr Hypertens Rep, 2016, 18(2):12. https://doi.org/10.1007/s11 906-015-0618-1 PMID: 26781252 PMCID: PMC5518745

[10] Zannad F, Mebazaa A, Juillière $Y$, Cohen-Solal A, Guize L, Alla $F$, Rougé $P$, Blin $P$, Barlet $M H$, Paolozzi L, Vincent C, Desnos M, Samii K; EFICA Investigators. Clinical profile, contemporary management and one-year mortality in patients with severe acute heart failure syndromes: the EFICA study. Eur J Heart Fail, 2006, 8(7):697-705. https://doi.org/10.1016/ j.ejheart.2006.01.001 PMID: 16516552

[11] Udani SM, Koyner JL. The effects of heart failure on renal function. Cardiol Clin, 2010, 8(3):453-465. https://doi.org/10. 1016/..ccl.2010.04.004 PMID: 20621250 PMCID: PMC2904358

[12] Thalmann M, Schima H, Wieselthaler G, Wolner E. Physiology of continuous blood flow in recipients of rotary cardiac assist devices. J Heart Lung Transplant, 2005, 24(3):237-245. https:// doi.org/10.1016/j.healun.2004.04.018 PMID: 15737748

[13] McAlister FA, Ezekowitz J, Tonelli M, Armstrong PW. Renal insufficiency and heart failure: prognostic and therapeutic implications from a prospective cohort study. Circulation, 2004, 109(8):1004-1009. https://doi.org/10.1161/01.CIR.00 00116764.53225.A9 PMID: 14769700

[14] Hasin T, Topilsky Y, Schirger JA, Li Z, Zhao Y, Boilson BA, Clavell AL, Rodeheffer RJ, Frantz RP, Edwards BS, Pereira NL, Joyce L, Daly R, Park SJ, Kushwaha SS. Changes in renal function after implantation of continuous-flow left ventricular assist devices. J Am Coll Cardiol, 2012, 59(1):26-36. https:// doi.org/10.1016/j.jacc.2011.09.038 PMID: 22192665

[15] Ma TKW, Kam KKH, Yan BP, Lam YY. Renin-angiotensinaldosterone system blockade for cardiovascular diseases: current status. Br J Pharmacol, 2010, 160(6):1273-1292. https:// doi.org/10.1111/j.1476-5381.2010.00750.x PMID: 20590619 PMCID: PMC2938800

[16] Ohnishi H, Itoh T, Nishinaka T, Tatsumi E, Fukuda T, Oshikawa M, Shioya K, Tsukiya T, Takewa Y, Homma A Uesho K, Sato K, Takano H, Taenaka Y. Morphological changes of the arterial systems in the kidney under prolonged continuous flow left heart bypass. Artif Organs, 2002, 26(11):974-979. https://doi.org/10.1046/j.1525-1594.2002.07135.x PMID: 12406155
[17] Felker GM, Rogers JG. Same bridge, new destinations rethinking paradigms for mechanical cardiac support in heart failure. J Am Coll Cardiol, 2006, 47(5):930-932. https://doi. org/10.1016/j.jacc.2005.09.070 PMID: 16516073

[18] James KB, McCarthy PM, Jaalouk S, Bravo EL, Betkowski A, Thomas JD, Nakatani S, Fouad-Tarazi FM. Plasma volume and its regulatory factors in congestive heart failure after implantation of long-term left ventricular assist devices. Circulation, 1996, 93(8):1515-1519. https://doi.org/10.1161/ 01.cir.93.8.1515 PMID: 8608619

[19] Jugdutt BI, Butler C. Ventricular unloading, tissue angiotensin II, matrix modulation, and function during left ventricular assist device support. Am J Coll Cardiol, 2007, 49(11):1175-1177. https://doi.org/10.1016/j.jacc.2006.12.022 PMID: 17367661

[20] Farquharson CAJ, Struthers AD. Gradual reactivation over time of vascular tissue angiotensin I to angiotensin II conversion during chronic lisinopril therapy in chronic heart failure. J Am Coll Cardiol, 2002, 39(5):767-775. https://doi.org/10.1016/s 0735-1097(02)01689-3 PMID: 11869839

[21] Burnett JC Jr, Knox FG. Renal interstitial pressure and sodium excretion during renal vein constriction. Am J Physiol, 1980, 238(4):F279-F282. https://doi.org/10.1152/ajprenal.1980.238. 4.F279 PMID: 7377299

[22] Nakamura T, Obata JE, Kimura H, Ohno S, Yoshida $\mathrm{Y}$, Kawachi $\mathrm{H}$, Shimizu F. Blocking angiotensin II ameliorates proteinuria and glomerular lesions in progressive mesangioproliferative glomerulonephritis. Kidney Int, 1999, 55(3):877889. https://doi.org/10.1046/j.1532-1755.1999.055003877.x PMID: 10027924

[23] Ferenbach DA, Bonventre JV. Mechanisms of maladaptive repair after AKI leading to accelerated kidney ageing and CKD. Nat Rev Nephrol, 2015, 11(5):264-276. https://doi.org/10. 1038/nrneph.2015.3 PMID: 25643664 PMCID: 4412815

[24] Grgic I, Campanholle G, Bijol V, Wang C, Sabbisetti VS, Ichimura T, Humphreys BD, Bonventre JV. Targeted proximal tubule injury triggers interstitial fibrosis and glomerulosclerosis. Kidney Int, 2012, 82(2):172-183. https://doi.org/10.1038/ki. 2012.20 PMID: 22437410 PMCID: PMC3480325

[25] Kagami S, Border WA, Miller DE, Noble NA. Angiotensin II stimulates extracellular matrix protein synthesis through induction of transforming growth factor-beta expression in rat glomerular mesangial cells. J Clin Invest, 1994, 93(6):24312437. https://doi.org/10.1172/JCl117251 PMID: 8200978 PMCID: PMC294451

[26] Bob FR, Gluhovschi Gh, Herman D, Bozdog Gh, Gluhovschi C Velciov S, Potencz E, Petrica L. Histological changes and immunohistochemical markers in the assessment of glomerulosclerosis in patients with glomerulonephritis. Rom J Morphol Embryol, 2011, 52(3 Suppl):1027-1032. PMID: 22119820

[27] Sakairi T, Abe Y, Kopp JB. TGF-beta1 reduces Wilms' tumor suppressor gene expression in podocytes. Nephrol Dial Transplant, 2011, 26(9):2746-2752. https://doi.org/10.1093/ ndt/gfr061 PMID: 21378152 PMCID: PMC3175051

[28] Rouschop KM, Sewnath ME, Claessen N, Roelofs JJ, Hoedemaeker I, van der Neut R, Aten J, Pals ST, Weening JJ, Florquin S. CD44 deficiency increases tubular damage but reduces renal fibrosis in obstructive nephropathy. J Am Soc Nephrol, 2004, 15(3):674-686. https://doi.org/10.1097/01. asn.0000115703.30835.96 PMID: 14978169

[29] Roeder SS, Barnes TJ, Lee JS, Kato I, Eng DG, Kaverina NV, Sunseri MW, Daniel C, Amann K, Pippin JW, Shankland SJ. Activated ERK1/2 increases CD44 in glomerular parietal epithelial cells leading to matrix expansion. Kidney Int, 2017 91(4):896-913. https://doi.org/10.1016/j.kint.2016.10.015 PMID: 27998643 PMCID: PMC5357449

[30] Chan GC, Eng DG, Miner JH, Alpers CE, Hudkins K, Chang A, Pippin JW, Shankland SJ. Differential expression of parietal epithelial cell and podocyte extracellular matrix proteins in focal segmental glomerulosclerosis and diabetic nephropathy. Am J Physiol Renal Physiol, 2019, 317(6):F1680-F1694. https:// doi.org/10.1152/ajprenal.00266.2019 PMID: 31630546 PMCID: PMC6962515

[31] Froes BP, de Almeida Araújo S, Bambirra EA, Oliveira EA, Simões E Silva AC, Pinheiro SVB. Is CD44 in glomerular parietal epithelial cells a pathological marker of renal function deterioration in primary focal segmental glomerulosclerosis? Pediatr Nephrol, 2017, 32(11):2165-2169. https://doi.org/10. 1007/s00467-017-3775-4 PMID: 28799058 
[32] Colnot DR, Roos JC, de Bree R, Wilhelm AJ, Kummer JA, Hanft G, Heider KH, Stehle G, Snow GB, van Dongen GA. Safety, biodistribution, pharmacokinetics, and immunegenicity of $99 \mathrm{mTc}$-labeled humanized monoclonal antibody BIWA 4 (bivatuzumab) in patients with squamous cell carcinoma of the head and neck. Cancer Immunol Immunother, 2003, 52(9):576-582. https://doi.org/10.1007/s00262-003-0396-5 PMID: 14627130

[33] Husain S, Ginawi I, Bashir Al, Kfoury H, Al Johani TE, Hagar H, Raddaoui L, Al Ghonaim M, Alsuwaida A. Focal and segmental glomerulosclerosis in murine models: a histological and ultrastructural characterization with immunohistochemistry correlation of glomerular CD44 and WT1 expression. Ultrastruct Pathol, 2018, 42(5):430-439. https://doi.org/10.1080/01913123.2018. 1501125 PMID: 30285525

[34] Benigni A, Morigi M, Rizzo P, Gagliardini E, Rota C, Abbate M, Ghezzi S, Remuzzi A, Remuzzi G. Inhibiting angiotensinconverting enzyme promotes renal repair by limiting progenitor cell proliferation and restoring the glomerular architecture. Am J Pathol, 2011, 179(2):628-638. https://doi.org/10.1016/j. ajpath.2011.04.003 PMID: 21718676 PMCID: PMC3157222

[35] Tomson C, Tomlinson LA. Stopping RAS inhibitors to minimize AKI: more harm than good? Clin J Am Soc Nephrol, 2019, 14(4):617-619. htpps://doi.org/10.2215/CJN.14021118 PMID: 30814113 PMCID: PMC6450359

[36] Giri S, Mahajan SK, Sen R, Sharma A. Effects of angiotensin converting enzyme inhibitor on renal function in patients of membranoproliferative glomerulonephritis with mild to moderate renal insufficiency. J Assoc Physicians India, 2002, 50(10): 1245-1249. PMID: 12568207

[37] Penescu M, Mandache E. The value of kidney biopsy in diabetes mellitus. Rom J Morphol Embryol, 2010, 51(1):1319. PMID: 20191114

[38] Zhang J, Yanez D, Floege A, Lichtnekert J, Krofft RD, Liu ZH, Pippin JW, Shankland SJ. ACE-inhibition increases podocyte number in experimental glomerular disease independent of proliferation. J Renin Angiotensin Aldosterone Syst, 2015,
16(2):234-248. https://doi.org/10.1177/1470320314543910 PMID: 25143333 PMCID: PMC4412792

[39] Larson D. VIII.60 - Glomerulonephritis (Bright's disease). In: Kiple KF (ed). The Cambridge world history of human disease. Part VIII: Major human diseases past and present. Cambridge University Press, New York, USA, 1993, 746-749. https://doi.org/10.1017/CHOL9780521332866.122

[40] Hedges SJ, Dehoney SB, Hooper JS, Amanzadeh J, Busti AJ. Evidence-based treatment recommendations for uremic bleeding. Nat Clin Pract Nephrol, 2007, 3(3):138-153. https://doi.org/ 10.1038/ncpneph0421 PMID: 17322926

[41] Tabit CE, Chen P, Kim GH, Fedson SE, Sayer G, Coplan MJ, Jeevanandam V, Uriel N, Liao JK. Elevated angiopoietin-2 level in patients with continuous-flow left ventricular assist devices leads to altered angiogenesis and is associated with higher nonsurgical bleeding. Circulation, 2016, 134(2):141152. https://doi.org/10.1161/CIRCULATIONAHA.115.019692 PMID: 27354285 PMCID: PMC4942355

[42] Grimm JC, Magruder JT, Kemp CD, Shah AS. Late complications following continuous-flow left ventricular assist device implantation. Front Surg, 2015, 2:42. https://doi.org/10.3389/ fsurg.2015.00042 PMID: 26347873 PMCID: PMC4541033

[43] Uzarski JS, Scott EW, McFetridge PS. Adaptation of endothelial cells to physiologically-modeled, variable shear stress. PLoS One, 2013, 8(2):e57004. https://doi.org/10.1371/journal.pone. 0057004 PMID: 23457646 PMCID: PMC3573044

[44] Aggarwal A, Gupta A, Kumar S, Baumblatt JA, Pauwaa S, Gallagher C, Treitman A, Pappas P, Tatooles A, Bhat G. Are blood stream infections associated with an increased risk of hemorrhagic stroke in patients with a left ventricular assist device? ASAIO J, 2012, 58(5):509-513. https://doi.org/10. 1097/MAT.0b013e318260c6a6 PMID: 22820918

[45] Yoshioka D, Okazaki S, Toda K, Murase S, Saito S, Domae K, Miyagawa S, Yoshikawa Y, Daimon T, Sakaguchi M, Sawa Y. Prevalence of cerebral microbleeds in patients with continuousflow left ventricular assist devices. J Am Heart Assoc, 2017 6(9):e005955. https://doi.org/10.1161/JAHA.117.005955 PMID: 28893764 PMCID: PMC5634264

\section{Corresponding author}

Simona Gurzu, Professor, MD, PhD, Vice-Dean of Faculty of Medicine in English, Head of Department of Pathology, George Emil Palade University of Medicine, Pharmacy, Science and Technology of Târgu Mureş, 38 Gheorghe Marinescu Street, 540142 Târgu Mureş, Mureş County, Romania; Phone +40745-673 550, Fax +40265-210 407, e-mail: simonagurzu@yahoo.com 